\title{
Renewable energy sources: Jobs created, skills required (and identified gaps), education and training
}

\author{
Charalampos Malamatenios ${ }^{*}$ \\ Centre for Renewable Energy Sources and Saving, Head of Training Department, 19th km Marathonos Avenue, \\ 19009 Pikermi-Attica, Greece
}

\begin{abstract}
As has been documented, renewables contribute significantly to employment growth, creating relatively more jobs than the fossil fuels they displace, an important fact due to the dramatic rise in unemployment experienced nowadays. The results of various studies made are presented, along with projections for the future. The jobs per installed megawatt of various renewable energy (RE) technologies are estimated for Greece and compared to conventional power production methods. Then, the variety of professions involved in each sub-sector of the RE industry (equipment manufacture and distribution, project development, construction and installation, operation and maintenance of plants) are presented, along with the recognized skills they should have to properly fulfil their tasks. Finally, selected initiatives undertaken by universities and vocational training providers aiming to address the identified skill shortages in all RE industry's parts are listed.
\end{abstract}

\section{Introduction}

The urgent need to drastically cut $\mathrm{CO}_{2}$ emissions makes the development of renewable energy (RE) technologies essential. Renewable Energy Sources (RES) bring other benefits as well, such as the provision of electricity in areas not connected to a central grid or where the grid is unreliable and back-up systems are required. RE can enable economic development in developing countries, most of which are geographically well-placed to be able to exploit the RE potential.

RES help address increasing concerns about future energy prices and energy security, in a context of a rapid global increase in demand for energy, driven mainly by rising living standards in developing countries. There are economic opportunities in RES, as several RE technologies are already competitive at market prices. In addition, decentralized electricity generation mobilizes small-scale private investments.

As it has become clear and has been documented in practice the last years, investments in renewables offer significant potential for creating employment opportunities, a key public policy concern in many countries. This is particularly important nowadays due to the dramatic increase in unemployment, being among the most onerous consequences of the crisis experienced by the world the last years. It is therefore important to keep in mind how the possible options and/or choices, especially in the energy sector, are affecting employment.

\footnotetext{
* e-mail: malam@cres.gr
}

There is significant employment potential associated with RE equipment manufacture and distribution, project development, construction and installation, as well as operation and maintenance of facilities, for all RE technologies. Dozens are the professions directly or indirectly associated with RES, and a range of core skills is important for them. However, skills gaps and labour shortages are also a reality. Therefore, there is scope for governments and for the RE sector to assist providers of relevant training and education to develop their training programs.

\section{Number of jobs created by RES}

Employment in RE sector has grown fast the last years, in close relation to the RES increased exploitation. According to UNEP estimations [1], in 2009 more than 3 million people worldwide were working directly in the sector, about half of them in the biofuels industry, with additional indirect jobs well beyond this figure. China accounted for the largest number, with more than 1.12 million workers estimated in the RE industry, with a growth rate of around 100,000 jobs per year.

In the last available relevant report, IRENA [2] estimates that in 2013 globally 6.5 million people were working directly or indirectly in the RE sector, based on a literature review and annual data collection from various sources. The status of RE employment is presented by technology and by selected countries, and its results (processed) are presented in Figure 1. Among all countries, China, Brazil, USA, India and Germany are the top five largest employers for RE. Solar PV and wind power are the two most dynamic RE sectors, according to IRENA. 


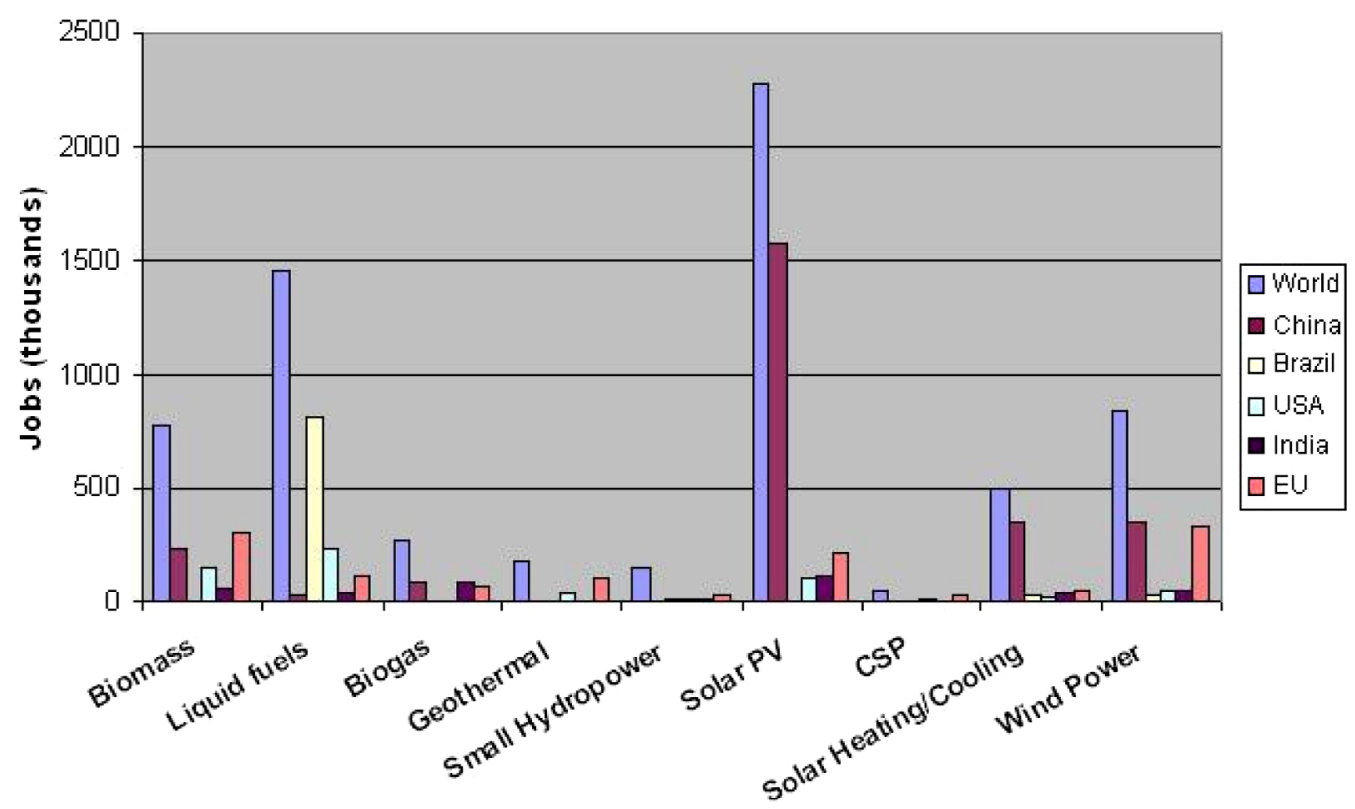

Fig. 1. RES jobs per technology and for selected countries in 2013, as recorded by IRENA [2].

Table 1. PV installations and job positions in Greece during 2010-2014. Source: S. Psomas.

\begin{tabular}{lcccrr}
\hline Year & 2010 & 2011 & 2012 & 2013 & 2014 \\
\hline Annual installed capacity $\left(\mathrm{MW}_{\mathrm{p}}\right)$ & 152.4 & 425.8 & 912.0 & 1042.5 & 16.7 \\
Cumulative installed capacity $\left(\mathrm{MW}_{\mathrm{p}}\right)$ & 198.5 & 624.3 & 1536.3 & 2578.8 & 2595.5 \\
Direct jobs & 4800 & 12,520 & 24,840 & 26,600 & 1300 \\
Indirect and entailed jobs & 5760 & 15,020 & 29,810 & 31,920 & 1560 \\
\hline
\end{tabular}

Various studies also exist regarding the future employment in RES. One released by Greenpeace International and EREC claims that the RE industry could provide 6.9 million jobs by 2030 , if world leaders seize the opportunity to invest in a greener future [3]. The EmployRES study (funded by EC) predicts that if the target of $20 \%$ penetration of RES is reached by 2020, 2.8 million jobs will be created in Europe (together with an increase in GDP by $1.1 \%$ ) [4]. According to the same study, the RE sector employed 1.4 million people and generated 58 billion $€$ in 2005.

An estimation/calculation of the jobs created per installed megawatt (MW) of various RE technologies is presented herein for Greece, a country where the impact of economic crisis is particularly acute, especially in unemployment. From the several calculation models of this type that exist nowadays, whose estimates are close enough since now there is extensive experience on which these models have been built, the methodology developed by the Millennium Institute on behalf of the International Trade Union Confederation [5] was selected to be used.

As RE jobs are created both locally (on the location of the power plant) and hyper-local (e.g. for the production of equipment), for calculating these jobs at the country level the percentage of $\mathrm{RE}$ equipment produced at national level - thus, not imported from a third country
- is requested. For the Greek conditions, the domestic share of equipment production (usually being of auxiliary type, such as mounts, cables, transformers, etc.) is of the order of $15 \%$.

Applying the above methodology first to the case of PVs, the resulting jobs are shown in Table 1 . The impact on employment in 2014 that had the suspension of approvals for new PV projects (which began in August 2012 and remained in force until April 2014) is clearly demonstrated. Employment in 2013 and 2014 was based essentially on projects that had been long matured from the licensing point of view and were simply implemented in this period.

Using the same methodology for the estimation of labour years (for direct jobs) created per new MW installed, the numbers shown in Figure 2 are derived. For the considered RE technologies, it can be seen that in the case of development and installation PVs produce more jobs, in the production of equipment wind energy comes first, while considering the long-term operation of the facilities biomass precedes by far (due to the need for collection, transportation and management of raw materials).

The picture changes drastically, with PVs taking the top position, when the direct jobs (namely, the labour years in a period of 20 years) per GWh produced by technology (Fig. 3) or per million $€$ of initial investment in each 


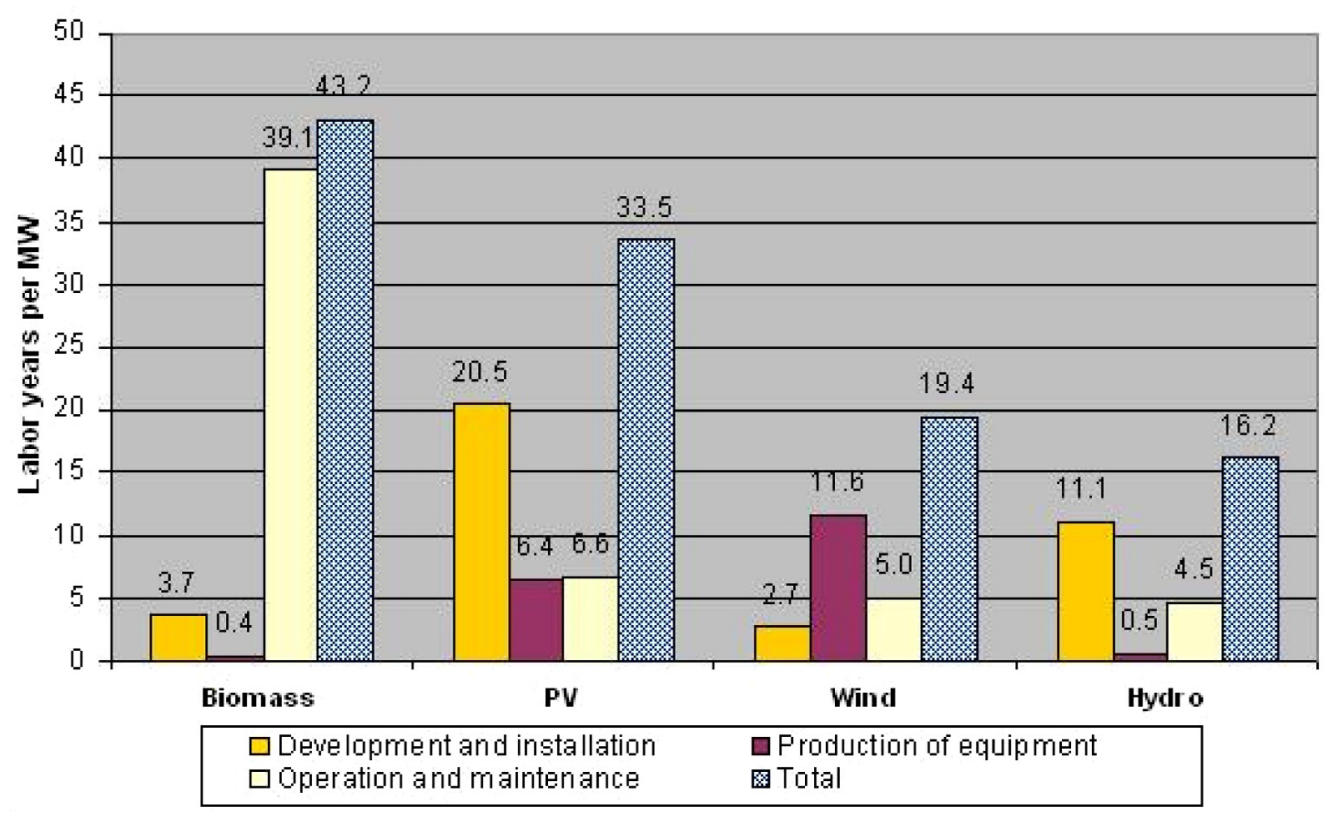

Fig. 2. Labour years (direct in 20 years) per MW of new RES investments. Source: S. Psomas.

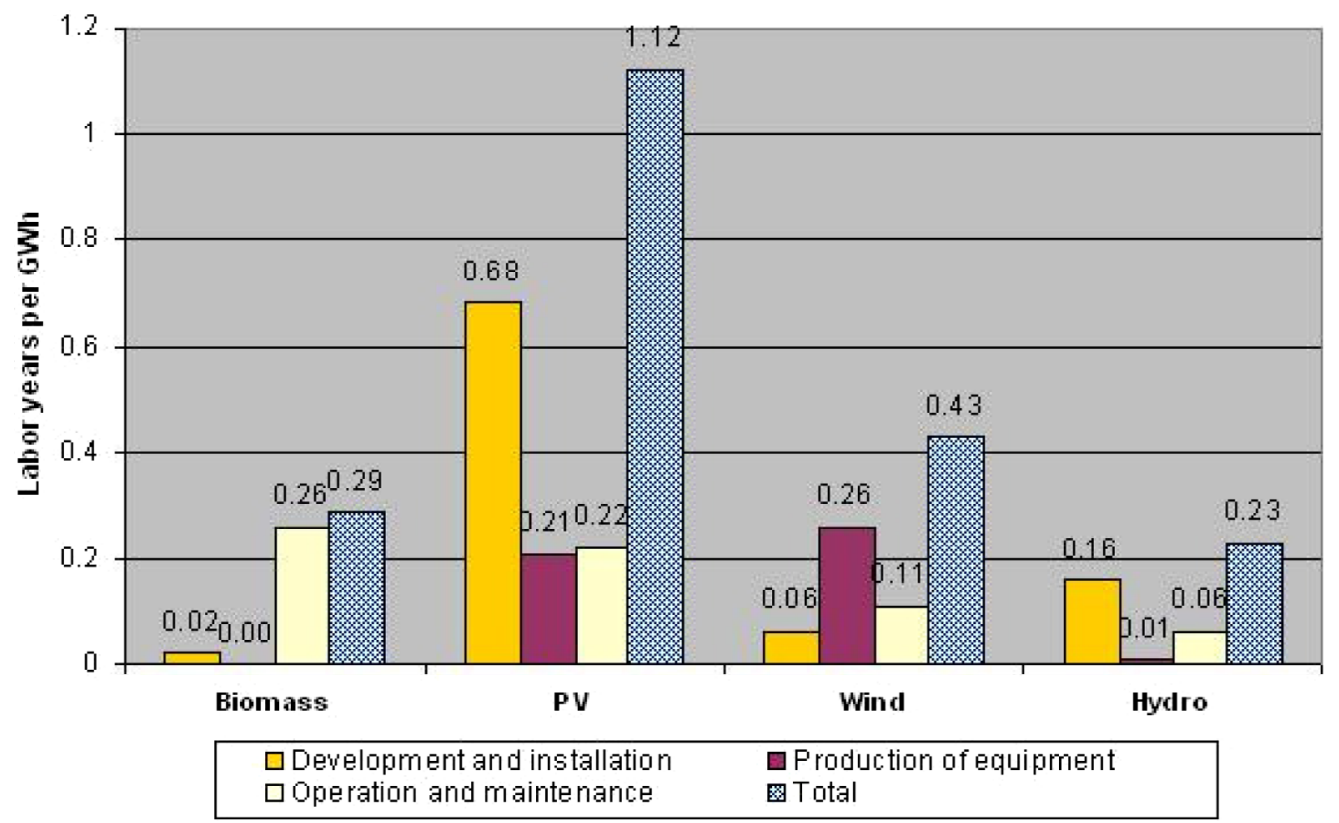

Fig. 3. Labour years per GWh from new RES investments. Source: S. Psomas.

technology (Fig. 4) are calculated. Especially in the latter case, the picture is very dynamic as the cost of some RE technologies (e.g. PV) constantly changes over time, even at a rapid pace.

For comparison purposes, a relevant study [6] for power plants that use as fuel lignite (including its mining) and natural gas in Greece, gives the following indexes: 0.238 labour years/GWh for lignite; 0.055 labour years/GWh for natural gas. Also, according to data of the main Greek power producer, the Public Power Corporation S.A. (PPC) for 2013 [7], PPC employed 4888 people in power plants and
3532 persons in the lignite mines, producing 37.5 TWh. This gives an equivalent rate of 0.225 labour years per $\mathrm{GWh}$ for all PPC's conventional units.

\section{RES job profiles, professions involved and skills required}

As already mentioned, employment in RES is not located in the energy producing facility only. The RE industry has 4 major (and distinguished) sub-sectors: 


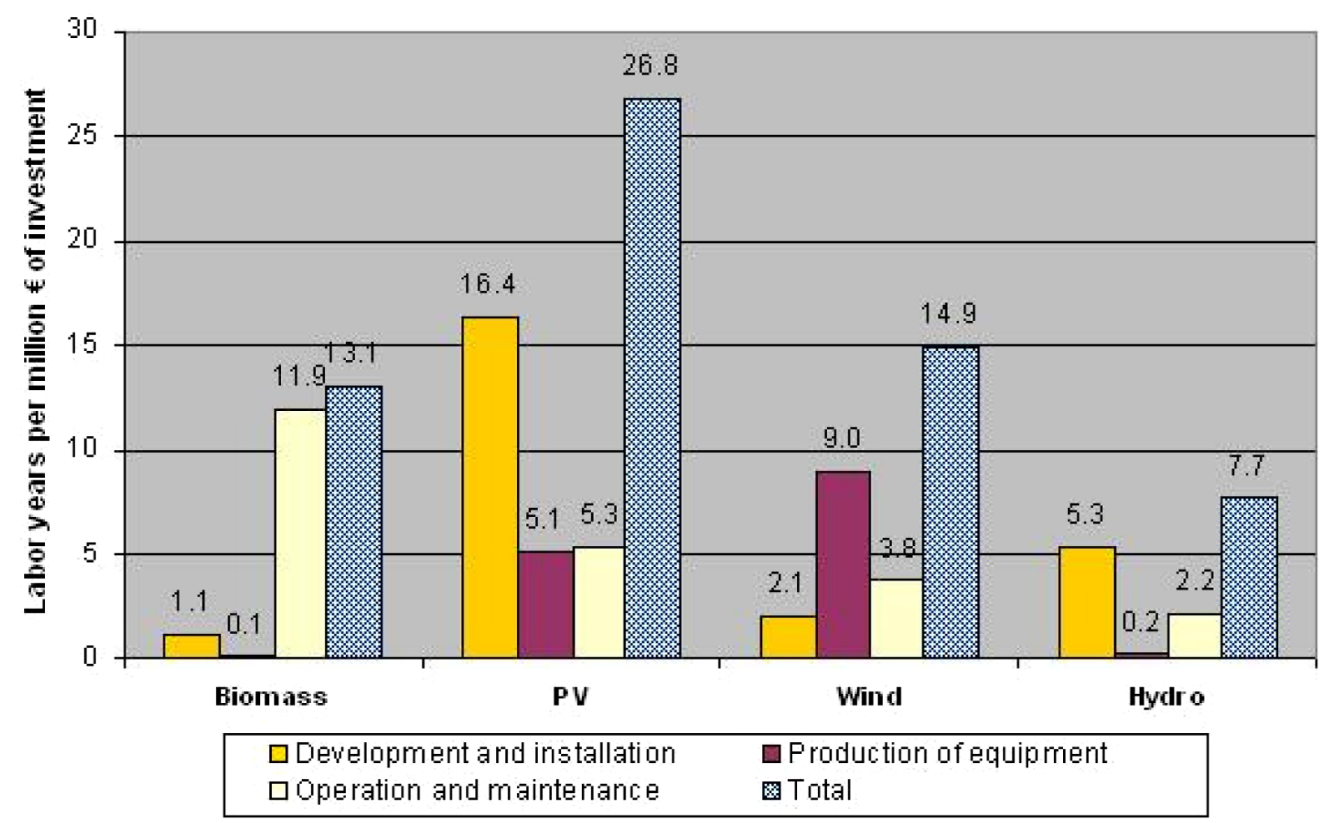

Fig. 4. Labour years per million $€$ of initial investment in RE technologies. Source: S. Psomas.

- manufacture and distribution of RE equipment, including the necessary research and development (R\&D);

- project development;

- construction and installation works for the development of RE projects;

- operation and maintenance (O\&M) of RE facilities.

There are also cross-cutting activities contributing to more than one sub-sector, such as policy/planning advice, energy consultancy, training, business development, marketing, etc. Bioenergy has an additional stage, the growing and harvesting of biomass.

The employment patterns in RE equipment manufacturing and distribution are similar to those in other capital investment goods industries. Quite different are the patterns in project development and in construction and installation, as the work is project based. The patterns of employment in the O\&M field are indeed more stable. Evidently, total employment tends to grow rapidly when significant new installations are implemented. This applies primarily to larger (in terms of installed capacity) projects. Smoother variation in demand over time appears if RES are introduced through a large number of smaller projects (e.g. PV systems in buildings).

Dozens are the professions directly or indirectly associated with RES. Technicians are the action men of the RE world: they work with their hands and with tools and machinery, special equipment and vehicles. They ensure that RE products are manufactured to high standards, plants are assembled according to the drawings, and RE devices are installed properly in buildings, or they may work in the dayto-day O\&M of RE facilities. In this category electricians, HVAC technicians, plumbers, drilling technicians, construction specialists, manufacturing processes operators, wind farm O\&M technicians, PV modules installers, logistics operators, automation \& control technicians, chemical laboratory assistants, etc. are included, just to name a few.
Technical Designers and Consultants are the technical brains behind all RE operations: they spot technical opportunities, come up with new ideas, solve problems, do the planning and ensure that new RE developments are sustainable in terms of society needs, economics and environmental protection. They may also specialise in R\&D to trial innovations which will improve the outputs and cost effectiveness of RE technologies. Engineers from mechanical, electrical, civil, power systems and software backgrounds, process or manufacturing engineers, landscape architects, geotechnical engineers, measurement \& control engineers, environmentalists, material scientists, biochemists, hydrologists, geologists, physicists, form this category.

Energy advisors are supporters and knowledge providers for individuals and companies involved in RE: they advise on national and/or regional policies related to RE planning and operation, as well as on energy management and efficiency. They can specialise in training ranging from the provision of general guidance for companies on new developments in $\mathrm{RE}$ to detailed training on specific subjects, such as installer accreditation. Planning consultants, land development advisors, environmental legal consultants, policy developers/local development officers, teachers/trainers, energy officers, energy advisors, health \& safety consultants are included herein.

Last, but not least, Business Development Executives are the business brains behind all RE operations: they spot new business opportunities, create proposals, negotiate with potential customers and ensure customer's needs are met all along the renewable energy supply chain. They can also specialise in business communications for creating marketing and media campaigns to help increase the uptake of RES. Professionals with the profile of business developers/analysts, marketing executives, financial, human resources and administration managers, technical sales representatives, public relations officers, etc. are included herein. 
Table 2. Principal occupations difficult to fill per sub-sector. Source: REN Alliance survey [8].

\begin{tabular}{ll}
\hline Sub-sector & Occupations \\
\hline Wind energy & $\begin{array}{l}\text { Project developers, service technicians, data analysts, electrical, computer, mechanical and } \\
\text { construction engineers }\end{array}$ \\
Solar energy & PV and solar thermal system installers and maintainers, building inspectors \\
Hydropower & $\begin{array}{l}\text { Electrical and operations \& maintenance engineers, technicians, trades persons, sustainability } \\
\text { specialists }\end{array}$ \\
Geothermal & Trainers, geothermal engineers \\
Bioenergy & R\&D and design engineers, service technicians, trainers \\
\hline
\end{tabular}

Apart from the specialized skills required for each one of the above listed categories of professionals, being essentially different according to the concerned RE technology, a range of core skills is important, as for example environmental awareness and motivation are highly desirable among RE industry employees at all levels. In addition, managers and consultants require dynamism, leadership, innovation, negotiation and strategic skills to get the most out of the opening up market opportunities. A survey of occupations in the RE sector by sub-sector and value chain segment is provided in the comprehensive report of ILO [8].

\section{Skills gaps and shortages - the role of education and training}

Most RE technologies (with hydropower being an exception) are still in their early stages of development and, in proportion to their current low level, are growing rapidly. From the national labour markets viewpoint the pattern is more varied, as for each RE technology there is limited activity in some countries, rapid growth in others, steady growth in capacity in some others, and a relatively mature industry elsewhere.

Problems with demand for skills and labour shortages in RES arise when activity takes off quickly, causing the demand for labour to switch suddenly from a minor to a significant level. This further occurs later, when the rate at which new $\mathrm{RE}$ projects are implemented increases substantially or falls rapidly. REN Alliance identified the principal occupations difficult to fill in many of its member countries (which include both developed and developing countries), as shown in Table 2 [8].

Apparently, a widespread skills shortage of engineers and technicians in all parts of the RE industry exists, which in many cases comes from a general trend of students not to follow engineering studies. Qualified design engineers with specific knowledge in particular $\mathrm{RE}$ technologies are especially needed. In wind energy, apart from engineers, specialized turbine technicians are needed. An engineering and technical skills gap appears in the hydropower sector in emerging countries, as well as a lack of qualified engineers and appropriately trained technicians in the bioenergy sector.

There are skills shortages in non-technical occupations also (Table 2). Legal advisors, sales specialists, inspectors, and economists in many cases lack specific skills, which are however critical for RES development. Skill shortages relate to knowledge about RE technologies and their social and economic benefits, environmental policies and regulations at international, national or regional level, specific measures launched by governments for assisting projects and other initiatives, etc. It has also been identified a widespread shortage of qualified trainers with RES specific skills.

It is a fact that the basic occupational skills required for many jobs in the RE industry are delivered through existing programs of education and training. University courses in electrical, civil, mechanical and environmental engineering, agriculture \& forestry, biosciences, geosciences, information technology, and a range of other disciplines provide the necessary foundation for professional level work in RE. Initial technical and vocational education \& training (ITVET) and apprenticeships in technical disciplines provide a good basis for working at technician level in $\mathrm{RE}$ industries.

On the other hand, retraining and/or supplementary training specifically focused on $\mathrm{RE}$ for workers with relevant skills who are looking to transfer to the $\mathrm{RE}$ industry from other parts of the energy sector, but also for graduates with less specialization, is a must. Retraining can in practice cover the largest part of the training needs, as most often construction and installation works are temporary and the labour needs may fluctuate. Those already working in the RE field require appropriate training to fill gaps in their existing skills or to up-skill them.

However, responding to rapid changes in demand for skills is often quite difficult for training and education providers, who may be slow to decide to focus specifically on the skills required for RE. Developing and running for the first time a course require a significant investment of time and effort, so providers may be reluctant to make this investment. Also, training and education providers are constrained by the expectations of their potential students/trainees. For example, a course offered before activity in RE takes off may not seem to be quite attractive.

Nevertheless, 'best practices' do exist with regard to the anticipation of educational needs. In the initial education and training level the course in installation and maintenance of wind farms offered by vocational training colleges in Spain, and the upper secondary vocational education as a RE technician specialized in solar systems offered by INETE in Portugal, are examples. Also many universities are shaping their courses to reflect the growth of interest in RE, such as Krakow University (Poland) that offers a 
degree course in Environmental Engineering-RES, and Newcastle University (UK) with its flexible degree program focused on RES.

In the postgraduate studies level, the MSc Program in RE offered by the CREST of Loughborough University (also through distance learning), and the European Master in $\mathrm{RE}$ developed by the Association of European $\mathrm{RE}$ Research Centres (EUREC), together with leading European universities active in RE education, are worth mentioning. EUREC's Master, which allows students to study in one of 4 different EU countries and then practice in another area of EU, is also exemplary from the point of view of the establishment of international linkages between qualifications in RE.

$\mathrm{RE}$ technologies and skills requirements are fairly uniform internationally, so there is indeed scope for standardizing the qualifications requirements. Transnational networks and initiatives make easier the acceptance of qualifications issued by institutions abroad, this way facilitating international mobility of workers. 'Best practices' are the Windskill training strategy for the entire European wind market (funded by the IEE Programme), and the Desertec University Network, an international academic network in the EU-MENA region aiming at contributing to the implementation of the Desertec Concept through the provision of education and training in solar power [9].

\section{Conclusions}

The generation of employment opportunities is a major policy priority in countries with high levels of unemployment and underemployment, be it a long-term issue or the immediate consequence of the economic recession. As described above, developing the RE capacities can make a significant contribution to job creation, being one of the benefits of exploiting the economic opportunities in $\mathrm{RE}$. However, to maximise the potential development of the RE industry, it is very important to get the right skills, in the right places, at the right time and in the right quantities.

A key difficulty in ensuring an adequate supply of skills is that the RE sector requires substantial numbers of engineers and technicians. Shortages in these occupations are common in developed countries and can also occur in developing countries when there is a sudden increase in demand. Another problem identified is that the patterns of demand for labour in the RE sector make it difficult for providers of education and training in skills relevant to $\mathrm{RE}$ to match their activity to industry needs.
Skills strategies for RES should be designed to mitigate this problem, and there is scope for governments and for the RE sector to assist providers of relevant training and education to develop their training programs. Social dialogue has a critical role to play both in identifying skills needed for the sector and in ensuring that adequate education and training provision is available. In this respect, the interaction between governments, employers/ companies and their associations, the federations of workers, and training providers is important for the adaptation or creation of new curricula (and qualification schemes) for RE.

To this end, the Occupational and Functional maps, as the one created for the RE sector in the UK by EU Skills [10] are crucial. An Occupational map is a report about an industry or sector (e.g. the RE one) providing information on the numbers employed, industry trends, job titles, progression routes and National Occupational Standards (NOS). A Functional map provides an overview of the types of major work tasks carried out in the industry/ sector, and describes the outcomes of the works in broad terms. These two documents set the scene for the subsequent work at national level and show how the NOS should be further produced and used.

\section{References}

1. United Nations Environment Programme (UNEP), Green economy. Renewable Energy. Investing in energy and resource efficiency, 2011

2. IRENA, Renewable Energy and Jobs. Annual Review, 2014

3. Greenpeace and EREC, Work for Climate Renewable Energy \&5 Green Jobs [R] evolution, 2009

4. Fraunhofer ISI, Energy Economics Group, Ecofys, Rütter + Partner, LEI and SEURECO, EmployRES: The impact of renewable energy policy on economic growth and employment in the European Union, Final Report, 2009

5. Millennium Institute, ITUC green jobs assessments research project - Methodology Overview, 2012

6. C. Tourkolias, S. Mirasgedis, D. Damigos, D. Diakoulaki, Employment benefits of electricity generation: a comparative assessment of lignite and natural gas power plants in Greece, Energy Policy 37, 4155 (2009)

7. PPC, Annual Report: https://www.dei.gr/el/i-dei/eni merwsi-ependutwn/etisia-deltia/annual-report-2013 (2013)

8. International Labour Office (ILO), Skills and occupational needs in renewable energy, 2011

9. DESERTEC Foundation, The DESERTEC Concept: http:// www.desertec.org/en/concept/2012

10. Adams Associates, Occupational and functional map for the renewable energy sector for Energy \& Utility Skills, 2007

Cite this article as: Charalampos Malamatenios, Renewable energy sources: Jobs created, skills required (and identified gaps), education and training, Renew. Energy Environ. Sustain. 1, 23 (2016) 